\title{
Recreating Beauty in Image in English Translation of Classical Chinese Poetry from the Perspective of "Three Beauties Theory"
}

\author{
Wu Chunrong ${ }^{1, *}$ \\ ${ }^{1}$ School of Foreign Languages, Sichuan University of Science \& Engineering, Zigong city, Sichuan province, China \\ *Correspondence: School of Foreign Languages, Sichuan University of Science \& Engineering, Xueyuan Road No. \\ 180, Zigong city, Sichuan province 643000, China. Tel: 86-138-900-9729. E-mail: 363493649@qq.com
}

Received: October 7, 2015

Accepted: November 6, 2015 Online Published: December 7, 2015

doi:10.5430/wjel.v5n4p26

URL: http://dx.doi.org/10.5430/wjel.v5n4p26

\begin{abstract}
As one of the representative figures of the Meter School, Xu Yuanchong, a Chinese outstanding translator contributes a lot for poetry translation both in practice and theory with his prolific translation works and his outstanding "Three Beauties Theory" (referred as TBT hereinafter). This paper first gives a brief introduction about different interpretations of Beauty, and then introduces Xu Yuanchong's "Three Beauties Theory" which means beauty in image, beauty in sound and beauty in form. As image is an important factor in poems writing and interpretation, this paper focuses on Xu's elaboration on beauty in image. By analyzing Chinese poetry's beauty in image and the feasibility of transmitting it from Chinese to English under the guide of TBT, this paper proves Xu's theory with examples. In the end this paper also points out some limitation in Prof. Xu's translation which includes imbalanced expression of TBT and too excessive speculation on beauty at the cost of faithfulness.
\end{abstract}

Keywords: Xu Yuanchong; Three Beauties Theory (TBT); Beauty in image; The transmitting of beauty in image

\section{Introduction}

Translation is not only a simple conversion process of language, but also an aesthetic and beauty-creating course, in which translators interpret the beauty of original works and transplant it into translated versions. The combination of translation and aesthetics manifest the pursuit and humanity conception of beauty by people. Aesthetics can be employed to guide the practice of translation, especially the classical Chinese translation.

What is beauty? Throughout the history, from the west to east, people's interpretation of beauty is a complexity. For example, Plato, philosopher of the ancient Greek, said that beauty was conception; Saint Augustine of Medieval, said that the beauty was the glory and effulgence of God; Nikolai Chernyshevsky put that beauty was life; Taoists in ancient China held that Heaven and Earth contained the brilliant beauty beyond words. In contrast, the Principles of Aesthetics (a work of a famous Italian Neo Hegelianism philosopher Benedetto Croce) tells us that beauty exits only in aesthetic relationship, it is inseparable from aesthetic subject and dependent on aesthetic object. Beauty is representation of spiritual abstraction, and the world of aesthetic feeling is a pure image world. Beauty exits in image. Zhu Guangqian, a Chinese anesthetist and writer as well as translator, says that the world of aesthetic feeling is the pure image world. Zong Baihua, a Chinese philosopher and aesthetic master, says that the blending of subjective live emotion and objective natural prospect create a lively and exquisite lingjing (meaning a fairyland), this is beauty. In classical Chinese poetry, beauty is embodied mainly in image, sound and form. Therefore, the translation of classical Chinese poetry demands particular attention on the delivery of beauty. This is an important way for our classical literacy to go abroad and enjoy popularity. Among the three beauties, that is, beauty in sound, beauty in form and beauty in image, beauty in image is this paper's focus.

\section{The Three Beauties Theory}

It is in 1979 that Xu Yuanchong, the Chinese poetry translator first put forward the Three Beauties Theory (referred to as TBT hereinafter), in other words, beauty in sound, beauty in image and beauty in form. Beauty in image refers to the reproduction of the artistic conception of the original poem and is definitely the most important aspect. Beauty 
in sound refers to the rhythm of poetry translated and the degree of rhythm corresponding to the original poetry. Beauty in form mainly refers to the numbers of lines and rows of poetry translated namely antithesis. Three beauties are, as I redefine, uniformity of contents, readability of sound and regularity of form. Generally speaking, it is nearly impossible to completely express these beauties at the same time. We may easily get ourselves trapped in translation for it is easy for us to pursue for one or two of the three beauties ignoring the rest of the three. Xu holds that similar in sense and image is a low standard for Chinese poetry translation whereas beauty in image is a higher demand. But most important of all, TBT is the most ideal aim that is hard to achieve. In regard to beauty in image, Prof. Xu Yuanchong puts it: the beauty in image is sometimes brought about by historical reason or the writers' subjective association, when it is rendered into another language; it is difficult to deliver the original text's beauty in image without the same historical background or similar association. Therefore, to express the original meaning of a poem, we must express not only the surface meaning, but also the deep implication, not only the literal meaning of the original words, but also the meaning between the lines. We should pay attention to diction and choose brilliant words which have similar images in original works, borrow the words which foreigners love to see and hear, and sometimes we may even be able to express the beauty in image by virtue of the beauty in sound and form. (Xu, 1979: 39) It is clear that the beauty's transmitting is not the translation itself, but a systematic process which involves diction, association and expression.

With respect to the beauty in sound, namely the beauty of pronunciation, Prof. Xu holds that translated version could borrow the delighting rhythm that the target readers enjoy, choose similar pronunciation rhyme and with the help of such methods as alliteration, musical sound and repetition, etc. When practicing translation himself, Xu always pays attention to rhythm and the number of sentences. Classical Chinese poetry has a strict restriction on level and oblique tones, rhythm and the number of sentences, just as "dancing with handcuffs and shackles". Prof. Xu Yuanchong puts on this "handcuffs and shackles" consciously in processing translating, and strives for the strict rhythm and the number of sentences, managing to make the translated version possess the similar superb harmony and sense of beauty as the original works. It can be easily found out that almost all the translated versions by Prof. Xu Yuanchong have a neat and tidy rhyme and meter, and a basic equal number of sentences.

As to the beauty in form, Prof. Xu Yuanchong argues that the beauty in form mainly depends on the respective length of sentences, and the translated version should have a similar form with the original one. In his work The Art of Translation (2006) and other published paper, Prof. Xu Yuanchong hammered at the importance of the beauties in sound and form in order to maintain that a translation of verse should keep the rhythm and the structure of original verse. He said: as for the beauty in form of poetry and lyrics, we should pay attention to their length and symmetry, at least, the similarity in form, in other words, the overall similarity in form is a must. (Xu, 1984) Generally speaking, it is difficult to create a translated verse that has a similar form or sound as that in the original one, but Prof. Xu Yuanchong dares to try this in spite of the hardships, producing a lot of excellent works that impressed many people. $\mathrm{Xu}$ 's theory was adopted by many scholars to demonstrate the translation of poetry, especially the translation of Chinese national literatures. (Chen, 2008; Zeng, 2012; Lv \& Zhao, 2015)

\section{Transmitting Beauty in Image through English Translation of Chinese Poetry}

\subsection{Characteristics of Classical Chinese Poetry}

Chinese poetry, as a unique style of Chinese character, contains special format and rhythm. Besides rhythm, a prominent feature of classical Chinese poetry, image creation and appreciation is another important feature. Chinese poetry can be divided, by the melody of poetry, into two categories: Guti poems (ancient poems) and Jinti poems (modern poems). Poetry can also be divided in different kinds from the prospective of their contents: narrative poems, lyric poems, farewell poems, frontier style poems, pastoral poems, nostalgic poems (historical poems), elegy poems and military poems. Collections of Guti poems (ancient poems) include The Book of Songs, The Songs of Chu, $\mathrm{Yueh}-\mathrm{Fu}$ (collected folk songs and ballads by government official in Han Dynasty), $\mathrm{Han}-\mathrm{Fu}$ (poetry in Han Dynasty), Folk Songs of the Northern and Southern Dynasties, etc. Classical Chinese poetry is a surging wave in the ancient China, especially in Tang and Song Dynasties. Ancient poets always use images in their poems to express a similar or interlinked emotion. When read and appreciate these poems, we need to unscramble and understand the images created in the poems to comprehend their meanings and thus enter into the artistic conception of the poems, tasting the emotions contained in the poems.

\subsection{Characteristics of Translating Chinese Classical Poetry into English}

The so-called image refers to the objective image which is turned into an artistic image after the subject's (the poets) 
unique emotional activities (creation activities). Contained with meaning, it is an objective image which incarnates the subjective affections and moods. In other words, it is the borrowing of an object to convey individuals' feelings. This shows that in addition to weighing every word in choosing diction and rhythm in translation of classical Chinese poetry due to the difference between the single syllable of Chinese character and the multi-syllables of English, the process of image transmitting plays a significant role in successful translation of Chinese poems into English ones. Thus it is the most important procedure in English translation of classical Chinese poetry to express original thoughts and feelings, images and artistic conceptions, to complete the beauty in rhythm and form on that basis. Here is a successful example of Xu Yuanchong's English translation of a poem written by Bai Juyi together with two other foreign translators'( Hber. A. Gile and W.J. Flecher) translation versions.

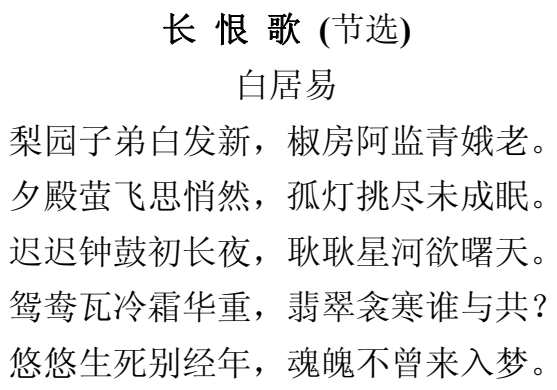

\section{The Everlasting Regret (Excerpts)}

$$
\text { By Bai Juyi }
$$

Actors, although still young, began to have hair grey;

Eunuchs and waiting maids looked old in palace deep.

Fireflies flitting the hall, mutely he pined away;

The lonely lamp-wick burned out; still he could not sleep.

Slowly beat drums and rang bells; night began to grow long;

Bright shone the Milky Way; daybreak seemed to come late.

The lovebird tiles grew chilly with hoar frost so strong,

And his kingfisher quilt was cold, not shared by a mate.

One long, long year the dead and the living were parted;

Her soul came not in dreams to see the brokenhearted.

(translated by $X u$ Yuanchong)

The hair of the Pear-Garden musicians

is white as though with age;

The guardians of the Pepper Chamber seem to him no longer young...

Slowly pass the watches, for the nights are now too long;

And brightly shine the constellations, as though dawn would never come.

(translated by Giles, quoted from Xu, 1984:50) 
The firefly flitting the room

Her spirit seemed to be;

The whole wick of his lamp he trimmed,

Yet sleep his eyes would flee.

How slowly through the dreary night

The bell the watches tolled.

How sleepless blinked the Milky Way,

Ere dawn the light unrolled!

When chill the roof where true love dwelt,

How thick the frost flakes form!

When cold the halcyon's coverlet,

Who then can make it warm?

(translated by Fletcher, qutoed from Xu, 1984:50)

The Everlasting Regret is a master piece by Bai Juyi of the Tang Dynasty. Taking Han Yuefu as genre, the long narrative poem tells about beautiful but tragic love story between the Tang Emperor Li Longji and his first lady Yang Yuhuan. It has been among the greatest Chinese classic poetry.

From above we can see that Prof. Xu Yuanchong pays attention to the rhyme and form so much that almost every object or we can say image has a counterpart in English version: in ancient Chinese poetry, poets often adopt the rhyming word that ends a line of verse, and Prof. Xu employs this method in almost all his works, the above example is a case in point where grey-away, deep-sleep, long-strong, late-mate are strictly rhymed (ababcdcd). Here he spares no effort to describe every detail without redundancies that original verse expressed out for the purpose of transmitting the intact artistic concept gorgeously, thus we may see the whole panorama simply through the English verse, which is a successful example of transmitting the beauty of images, sounds and forms. Some people argue that this verse is not a brilliant one because it looks like doggerel in English culture. I could not agree with this view for that this is a translated verse from ancient Chinese poetry, which features a complete distinction of language character from English, which belongs to a totally different language family rather than Sino-Tibetan. Only in this way can we find a better way to enhance intercultural communications.

But in English poems, the blank verse seems to dominate people's minds. They prefer to use simple but meaningful words, brief but powerful sentences, and they favor ellipsis. From two translated verses by Giles and Fletcher above we can see that rhythm is not so obvious in their works, but the simplicity of them draws readers to think more and recollect more. Though they do understand what the original poem wants to express, they fail to transmit the beauty of images for in ancient Chinese poetry, images are among the most important to express emotions of authors. I do believe that they can rack their brains to strike up rhythmic words to make a verse, but that's not what they thought to be right and perfect. Their translated verses are more like original works of themselves than verses of classical Chinese poems.

However, I am not saying that the verse of Prof. Xu is better than others; the three versions have their own highlights. As the saying goes, every coin has two sides, so as to Xu's translation of Chinese ancient poetry. While Xu endeavors to achieve the effect of Three Beauties, some demerits and limitations appear in his translations, which I will dwell on later.

\section{On Xu's Excessive Exploration of Three Beauties}

\subsection{The Lost of the Beauty in Image}

As an outstanding practical translator and theorist of translation, Prof. Xu Yuanchong's endeavor to explore the field of translating ancient Chinese poetry has a great impact on modern research of translation, and provides an indicator for the late translators and scholars who study translation. However, due to the extremely subjective concept of beauty and the existence of different personal aesthetic styles and translation styles, Prof. Xu has a few verses translated through the experience and style of himself that give rise to controversies and worth discussing, being an ideal state the three beauties. In a few, if not few cases, he partially racks his brain instead of transmitting the beauty 
of image but the achievement of beauties of sound and form, but the effect was the other way around.

For instance,

掬水月在手，弄花香满衣。(春山月夜-于良史)

Drinking water, you drink moonbeams;

Plucking flowers, you pluck sweet dreams.

(translated by Xu Yuanchong)

Here "粙"means to lift water with two hands, but Prof. Xu chooses the word "Drinking" to match the word "Plucking" below in sound regardless of the meaning "lift". Besides, “香满衣” refers to the balmiest cloth attributed to foundling flowers, but Prof. Xu assimilates "cloth" to "sweet dreams" for the same reason in spite of the images in the original verse. Here Prof. Xu adds unexpected images and meanings to his verse in order to realize the beauties in sound and form.

寂寂竟何待, 朝朝空自归。欲寻芳草去, 惜与故人违。(留别王维-孟浩然)

Lonely, lonely, what is there to hope for?

Day by day I come back without an end.

I would seek fragrant grass in native shore.

How I regret to part with my old friend!

(trasnlated by $X u$ Yuanchong)

Here the first two lines mean that: what else can I hope for despite my loneliness? For everyday I come back home with despair. I want to realize my ambitions and ideas, but regret to separate from my friend. However, Prof. Xu adds a specific location "native shore" without a suitable reason, which generates a suspicion that he did so to match the sound and form of lines above. Simply, he adds meaningless and subjective words (images). Here, fragrant grass refers to the poet's ideas and to seek fragrant grass refers to seek seclusion or realize ideas, but Prof. Xu remains this image without noting that, which may cause troublesome understanding of foreign readers.

\subsection{Excessively Transmitting the Beauty in Image}

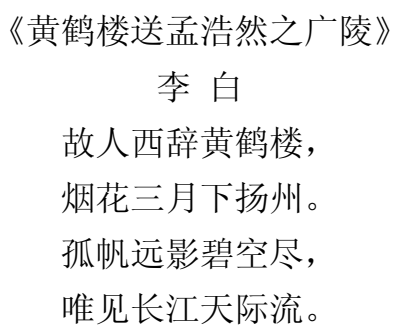

\section{Seeing Meng Hao-ran Off At Yellow Crane Tower}

by Li Bai

My friend has left the west where the Yellow Crane towers;

For River Town green with willows and red with flowers.

His lessening sail is lost in the boundless blue sky;

Where I see but the endless River rolling by.

Notes;

(translated by $X u$ Yuanchong)

1. Meng Haoran: Li Bai's friend who was also a famous poet in Tang Dynasty

2. Guangling: a place

3. Yellow Crane Tower: Being located at the Snake Mountain in Hubei Province

Actually, this translation on the one hand is an excellent verse because Prof. Xu translated this poem in an artistic prospective: he did not translate it word by word; on the contrary, he adopted the method of translating artistic concept rather than literal images. On the other hand, however, this translation is dishonest for the translator depicted 
images in other words and images that do not belong to the original one: green willows and red flowers refers to a colorful image of spring, but the original poem mentioned only a March. Secondly, despite the fragment of second and fourth lines, he added "lessening" to modify the sail while the original one stressed on loneliness. This is an example of excessive ornament on translated verse.

Here is another translated version by Yang Xianyi, a prolific and top-rate prose translator without a musical sense. After I have read some of his and his wife's works I found that almost all the works of them are accurate and detailed but without any rhythm or melody.

\section{Seeing Meng Haoran Off From Yellow Crane Tower}

\section{At Yellow Crane Tower in the west my old friend says farewell,}

In the mist and flowers of spring he goes down to Yangzhou.

Lonely sail, distant shadow, vanish in blue emptiness,

All I see is the great river flowing into the far horizon.

Here we can see that every specific object (image) has been rendered with appropriate modifiers. This is an honest translation, in terms of images, of course. It is suitable to say that this version was translated literally, and that it looks like a poem with short line breaks, but actually a small prose without cadence. What if we combine the two with their own advantages: integrating the sound and form of the Xu's version and the image and precise of Yang's version. I dare not to try because of capacity-constrained.

There is another example which shows a more apparent excessive transmitting of images.

$$
\begin{gathered}
\text { 清 明 } \\
\text { 杜 牧 } \\
\text { 清明时节雨纷纷, } \\
\text { 路上行人欲断魂. } \\
\text { 借问酒家何处有, } \\
\text { 牧童遥指杏花村. }
\end{gathered}
$$

A drizzling rain falls like tears on the Mourning Day;

The mourner's heart is going to break on his way.

Where can a wineshop be found to drown his sad hours?

A cowherd points to a cot 'mid apricot flowers.

(translated by $X u$ Yuanchong)

It drizzles endless during the rainy season in spring,

Travelers along the road look gloomy and miserable.

When I ask a shepherd boy where I can find a tavern,

He points at a distant hamlet nestling amidst apricot blossoms.

(transalted by Yang Xianyi, 2001)

It is easy to be detected that Prof. Xu was reasonably suspected to be excessive on transmitting the beauty of image in his translation, although he does do well in pronunciation and form, and that despite its rhythm-limited words and sentences, Yang's version basically restored the artistic concept of the original poem. Apparently, the latter one is the better one in translating artistic concept of this ancient Chinese poem.

But this is not saying that Xu's version is worse than Yang's, for it just laterally indicates the difficulty in transmitting the three beauties.

\section{Conclusion}

From what mentioned above we can come to the conclusion that translation versions are different from each other on the basis of focuses. In the listed examples we can say that Prof. Xu Yuanchong acts as a creator rather than a 
translator, which leads to a subjectivity matter that doesn't pertain to the discussion part of this paper. As the proverb says, one thousand readers, one thousand "Hamlets", and that is the difficult part in translation, especially the English translation of ancient Chinese poetry.

Dong Chun, the editor of the Europe Journal describes his feelings about literary translation that it is like biting bitter gourd, tasting bitter but a pleasure within.

Poetry is a work of art featuring highly condensed and unified form and spirit. Translation itself is a process of beautifying in which translator interpret the original beauty to the other.

As a learner of translation, we should learn the excelsior spirit and rigorous attitude on pursuing perfection of Prof. $\mathrm{Xu}$ Yuanchong, because when translating literary works, we are not only demanded to translate the message faithfully, but also the original works' sense of beauty to target readers.

Nevertheless, to completely convey the three beauties in English translation of ancient Chinese poetry is an ideal proposition that proves to be hardly possible without any abnegation in one or two of the three beauties in terms of inter-translation of Chinese and English poetry. Therefore, we should adopt a critical and scientific attitude toward the TBT, and conduct our practices according to the specific conditions.

\section{References}

Chen, Guojian. (2008, January). On Translation of Ancient Chinese Poetry - Comments on the Theory of 'Three Beauties' in Translation by Xu Yuanchong. Journal of Guangdong University of Foreign Studies, 19(1), 20-24.

Li, Zhaofang \& Niu, Junping. (2015, August). Translation of "The Moon Over the River on a Spring Night" Based on Principle of "Three Beauties". Foreign Language and Literature, 50(4), 45-50.

Xu, Yuanchong. (1979, February). How to Translate Mao Zedong's Poetry. Foreign Language Teaching \& Research, $18(2), 1-6$.

$\mathrm{Xu}$, Yuanchong. (2006). The Art of Translation. Beijing: Wuzhou communication Publishing Press.

Xu, Yuanhong. (1984, June). Bai Juyi's "The Everlasting Regret" and Its English Translation. Journal of Hei Long Jiang University, 22(3), 49-61.

Yang, Xianyi \& Dai, Naidie. (2001). Tang Poems and Their Translation. Beijing: Foreign Language Publishing Press.

Zeng, Xianghong. (2012, November). The Translation of Ancient Poetry from the Perspective of "Three Beauties Theory"-Taking Xu Yuanchong's Translation of Chinese Ancient Poetry as An example. Jiangxi Social Science, 45(11), 246-249. 